\section{ENTREPRENEURSHIP EDUCATION IN DEVELOPING PEOPLE'S ECONOMY}

\author{
PENDIDIKAN KEWIRAUSAHAAN \\ DALAM MENGEMBANGKAN \\ EKONOMI KERAKYATAN
}

Jurnal Pendidikan Luar Sekolah

http://kolokium.ppj.unp.ac.id/ Jurusan Pendidikan Luar Sekolah Fakultas Ilmu Pendidikan Universitas Negeri Padang

Sumatera Barat, Indonesia

Volume 7, Nomor 1, April 2019 DOI: 10.24036/kolokium-pls.v7i1.21

\author{
Irmawita ${ }^{1,2}$ \\ 1Jurusan Pendidikan Luar Sekolah Fakultas Ilmu Pendidikan Universitas Negeri Padang \\ 2Email:irmawita@fip.unp.ac.id
}

\begin{abstract}
The various impacts that have been taken in the era of globalization and increasingly widespread transformation will have positive and negative impacts. Various potentials faced, both natural resources and human resources must be a priority to be developed, especially by the Study Program of Non Formal Education as one of the educational institutions that must be a solution for an increasingly developing age. One way that can be taken to develop human resources, especially the PLS study program is through student self-development towards the cultivation of entrepreneurial spirit in aspects of life. It is very important to do outside school education that is closely related to education for the community to continue to be a pioneer in the development people's economy which has an entrepreneurial spirit, devotion and conduct economic business through koperasi and small and medium enterprises so that intact human resources can be built independent, productive and able to become the hope of the nation that responds to the flow of globalization with various challenges. The challenge of globalization towards self-reliance and productive endeavors for students of study programs outside of school is a shared hope towards people's economy and the transparent world of work and accountability.
\end{abstract}

Keywords: Entrepreneurship Education, Entrepreneurship, People's Economy

\begin{abstract}
ABSTRAK
Berbagai dampak yang ditempuh dalam era globalisasi dan transformasi yang semakin meluas akan menimbulkan dampak positif dan negatif. Berbagai potensi yang dihadapi, baik sumber daya alam maupun sumber daya manusia haruslah menjadi prioritas untuk dikembangkan, khususnya oleh program studi Pendidikan Luar Sekolah sebagai salah satu lembaga pendidikan yang memiliki kewajiban untuk dapat menjadi solusi bagi zaman yang semakin berkembang. Salah satu cara yang dapat ditempuh untuk mengembangkan sumber daya manusia, khususnya program studi PLS adalah melalui pengembangan diri mahasiswa menuju penanaman jiwa wirausaha di dalam aspek kehidupan. Penting sekali dilakukan oleh pendidikan luar sekolah yang erat dengan pendidikan bagi masyarakat untuk terus menjadi pionir dalam pengembangan ekonomi kerakyatan yang berjiwa wirausaha mandiri, bertaqwa dan melakukan usaha perekonomian melalui koperasi dan usaha kecil menengah sehingga dapat terbangun sumber daya manusia yang utuh, mandiri, produktif dan mampu menjadi harapan
\end{abstract}


bangsa yang menyikapi arus globalisasi dengan berbagai tantangan yang ada. Tantangan globalisasi menuju kemandirian dan usaha produktif bagi mahasiswa program studi pendidikan luar sekolah menjadi harapan bersama menuju ekonomi kerakyatan dan dunia kerja yang tranparan dan akuntabilitas.

Kata Kunci: Pendidikan Kewirausahaan, Entrepreneurship, Ekonomi Kerakyatan

\section{PENDAHULUAN}

Pendidikan kewirausahaan dalam rangka meningkatkan ekonomi kerakyatan yang berkepanjangan masih dirasakan pada saat ini, dan masih mencekam kehidupan sebagian besar dari masyarakat Indonesia (Tohani, 2015). Globalisasi yang pada awalnya diharapkan akan membawa kita ke zaman emas yaitu cita-cita akan masa depan yang lebih cerah, merubah suatu kenyataan pahit, globalisasi telah menjadi ilusi, pertanyaan yang muncul apakah kita hanya diam saja? Ataukah merasa tertipu karena kepandaian orang lain?, tentu jawabannya tidak sampai disitu. Banyak cara dan upaya serta kegiatan yang dapat dilakukan terutama kita sebagai seorang praktisi PLS yang selalu dituntut oleh misinya sebagai pengembang serta memajukan potensi yang ada untuk dapat mendayagunakan segala sumber daya tersebut baik yang telah disediakan oleh alam maupun oleh manusia itu sendiri (Karokaro, 2011; Syamsi, 2010).

Pendidikan luar sekolah merupakan jurusan yang memiliki potensi yang cukup besar dalam mengembangkan kehidupan dan usaha produktif dan inovatif. (1) Strategi saat ini yang diperkirakan di masa mendatang perlu dianalisa secara mantap, tepat dan cepat agar globalisasi yang sarat dengan perubahan diberbagai kehidupan dapat menjaga dan memelihara "buman survival" sehingga manusia sebagai individu bisa memanfaatkan peluang peluang yang ada karena globalisasi itu sendiri merupakan buatan manusia. (2) Kewirausahaan menuju ekonomi kerakyatan yang telah teruji ketahanannya terutama waktu krisis ekonomi perlu dikembangkan melalui pendidikan kewirausahaan. Sebagai proses budaya melalui pendidikan ia akan tumbuh dan berkembang dalam alur kebudayaan setiap anggota masyarakat yang didasari oleh kekuatan agama yang dianut oleh masyarakat sehingga menjadi tata cara yang mengakar kuat dalam kehidupan masyarakat. Aktualiasi dirinya mewujudkan aspirasinya secara mandiri dan merupakan tuntutan kebutuhan manusia merupakan prasyarat pokok bagi perkembangan masyarakat maju (Solfema, 2017a).

Bertitik tolak dari ketiga unsur di atas, maka upaya untuk mengembangkan pendidikan kewirausahaan dan budaya wirausaha melalui ekonomi kerakyatan bagi mahasiswa program studi Pendidikan Luar Sekolah merupakan suatu upaya untuk terciptanya kualitas sumber daya manusia (SDM) yang memiliki keseimbangan penguasaan ilmu pengetahuan, karsa dan karya dengan moral penghayatan iman dan taqwa kepada Allah SWT.

Pendidikan Kewirausahaan dalam meningkatkan ekonomi kerakyatan di kalangan mahasiswa PLS lebih memotivasi dalam memperjuangkan dan memanfaatkan dalam mencapai dunia kerja melalui pendidikan. Isi materi dalam tulisan ini menjelaskan tentang konsep pendidikan kewirausahaan, pendidikan ekonomi kerakyatan melalui koperasi dan Usaha Kecil dan Menengah, dan usaha kemandirian. 


\section{KONSEP PENDIDIKAN KEWIRAUSAHAAN DAN PENDIDIKAN KECAKAPAN HIDUP}

Istilah pendidikan kewirausahaan mengacu kepada upaya untuk membantu memenuhi kebutuhan masyarakat yang semakin meningkat memperluas kesempatan kerja, turut serta dalam upaya mengakhiri ketergantungan kepada luar negeri dan di dalam fungsifungsi tersebut selalu tunduk pada tertib hukum lingkungannya (Solfema, 2017a; Wiratno, 2012). Mereka adalah orang-orang yang cermat dan penuh perhitungan dalam mengejar peluang-peluang memenuhi kebutuhan dan keinginan melalui inovasi dan mengambil keputusan yang hendak dicapai (Purnomo, 2015).

Kewirausahaan adalah suatu proses seseorang yang mempunyai sikap mental positif yang berorientasi pada tindakan dan mempunyai motivasi tinggi dalam mengembangkan resiko saat mengejar tujuan (Badan Penelitian dan Pengembangan Pusat Kurikulum Kementerian Pendidikan Nasional, 2010). Jadi setiap orang bisa menjadi wirausahawan asal mau dan mempunyai kesempatan untuk belajar berwirausaha. Kemampuan berwirausaha merupakan suatu keinginan dan kemauan untuk menciptakan nilai tambah dan keuntungan di pasaran melalui proses pengkombinasian sumber daya dengan cara-cara baru dan berbeda melalui kemampuan aktif, kreatif dan inovatif serta bermanfaat (Sari \& Rahayu, 2019; Solfema, 2017b).

Istilah pendidikan kecakapan hidup mengandung dua pengertian yaitu pendidikan dan kecakapan hidup. Pendidikan adalah usaha sadar untuk menyiapkan peserta didik melalui kegiatan bimbingan, pengajaran, dan atau latihan bagi peranannya pada masa yang akan datang (Presiden Republik Indonesia, 2003). Kecakapan hidup adalah kecakapan yang dimiliki seseorang untuk berani menghadapi problema dan tantangan hidup dan kehidupan dengan wajar tanpa merasa tertekan kemudian secara proaktif dan kreatif mencari kerja sehingga menemukan solusi sehingga akhirnya mampu mengatasinya. Keterampilan hidup adalah konsep yang bermaksud memberi bekal pengetahuan, keterampilan pengetahuan fungsional dan perubahan sikap pada seseorang untuk bekerja dan berusaha mandiri sehingga memperoleh penghasilan yang layak untuk memenuhi kebutuhan hidupnya (Usman, 2010). Konep pendidikan kecakapan hidup memiliki cakupan yang luas berinteraksi antara pengetahuan dan keterampilan yang diyakini sebagai unsur penting untuk dapat mandiri. Oleh karena itu, membimbing, melatih dan membelajarkan peserta didik menjadi bekal dalam menghadapi masa depannya (Shaumi, 2015). Dari pengertian tersebut diperoleh kandungan bahwa kecakapan hidup bukan sekedar mampu melakukan suatu pekerjaan, dan berusaha untuk memenuhi kebutuhan hidupnya, tetapi juga mampu memecahkan masalah-masalah yang dihadapi dalam hidupnya.

Pendidikan berbasis kecakapan hidup pada hakekatnya merupakan pendidikan pada penguasaan keterampilan, keahlian dan kemahiran bekerja yang dapat dihandalkan sebagai bekal hidup (Muhdi, Senowarsito, \& S., 2012). Tujuan pendidikan kecakapan hidup secara umum adalah meningkatkan pengetahuan dan keterampilan serta sikap warga belajar dibidang tertentu, sesuai dengan bakat, kemauan dan minatnya sehingga memiliki bekal pengetahuan untuk bekerja yang dapat mendatangkan penghasilan guna memenuhi kebutuhan hidupnya. Sedangkan secara khusus bertujuan memberikan pelayanan pendidikan kecakapan hidup kepada peserta didik untuk: (a) Memiliki pengetahuan, keterampilan dan dasar sikap yang dibutuhkan dalam memasuki dunia kerja, baik bekerja mandiri (wirausaha) maupun bekerja pada suatu perusahaan produksi. (b) memiliki motivasi yang tinggi serta 
dapat menghasilkan karya-karya yang unggul dan mampu bersaing di pasar global.(c) Memiliki kesadaran yang tinggi pentingnya pendidikan yang ditompang oleh empat pilar ( learning to know, learning to do, learning to be, dan learning to live togerther)(d) Mempunyai kesempatan untuk memperoleh pendidikan dalam rangka dalam mewujudkan keadilan pendidikan bagi setiap lapisan masyarakat (Presiden Republik Indonesia, 2003).

Entrepreneurship adalah istilah yang tidak asing lagi tentang kewirausahaan, mengandung arti bahwa entrepreneur is behavior that is dynamic risk talking, reactive and growt oriented, entrepreneur is a person who is willing to take action to porpoise opportunities in situations view as problem or threats. Pandangan umum seorang entrepreneur adalah seorang penemu bisnis yang sama sekali yang baru dan mampu mengembangkan menjadi perusahaan yang mencapai sukses secara luas. Contoh: Microsolf, WolMart, Agna Golden Missisipi dan lain sebagainya.

Enterpreneur tidak terbatas pada perusahaan besar tetapi juga perusahaan perusahaan kecil. Keberanian seseorang mengambil resiko, membuka toko kelontong atau bisnis yang dijalankan oleh dirinya sendiri juga merupakan entrepreneur. Entrepreneurship adalah pengembangan prilaku kewirausahaan dalam lingkup internal organisasi yang lebih besar (dalam bentuk perusahaan korporat). Entrepreneurship muncul karena kebutuhan perusahaan untuk mengembangkan strategi bisnisunit dalam meningkatkan Competitive agar perusahaan mampu meningkatkan parenting advantage. Contoh entrepreneur plus Indonesia yang berhasil adalah Ir. Ciputra yang memiliki group Ciputra dengan bisnis utama dalam bidang property, tentu masih banyak lagi contoh-contoh yang lainnya. Menurut J.A. Schumpeter yang dapat digolongkan menjadi wirausaha adalah seorang innovator, sebagai individu yang mempunyai naluri untuk melihat materi sedemikian rupa dan kemudian terbukti benar mempunyai semangat, kemampuan dan pikiran untuk menaklukkan cara berfikir lamban dan malas.

Manusia wirausaha memiliki moral yang tinggi, salah satunya tanggung jawab atau kewajiban manusia adalah mengenal, menyadari, mengingat dan bersyukur kepada yang Khalik Maha Penciptanya yang telah memberi anugerah kepada kita. Manusia yang bermoral tinggi memiliki kemerdekaan bathin, ditandai dengan adanya keselarasan antara keinginankeinginan dengan pandangan dalam diri seseorang, adanya keselarasan antara keuangan dengan pengenalan diri. Dengan adanya kemerdekaan bathin ini maka tumbuhlah keberanian seseorang untuk berbuat dan berusaha untuk maju.

Seseorang untuk menjadi wirausaha yang sukses memiliki karakteristik sebagai berikut: (1) Mempunyai Courage, yaitu memiliki nyali atau keberanian untuk mengambil resiko. (2) Mempunyai Conviction, yaitu keyakinan melakukan apa yang dikatakan. (3)Mempunyai Confidence, yaitu kepercayaan diri untuk bicara akan kebenaran (4) Mempunyai Commitment, yaitu komitmen apa yang mereka lakukan adalah benar dan ini akan membuat perbedaan. (5) Mempunyai Companianote, yaitu kompasion hati yang penuh kasih sayang, simpati, pengertian bahwa anda adalah bagian dari umat manusia. (6) Mempunyai Connection, yaitu koneksi untuk membantu meyakinkan, mendidik dan memberi pengarahan. (7) Mempunyai prudence, yaitu hati dalam memberi keputusan pemikiran secara matang. (8) Mempunyai Perseverance, yaitu keteguhan hati untuk terus melangkah dijalan yang sama berulangkali. (9) Mempunyai Personasiveness, yaitu kepandaian orang lain agar dapat menjual ide- idenya. (10) Mempunyai Patience, yaitu kesabaran yang tinggi untuk bertindak agar tercapai perubahan yang positif. (11) Mempunyai sikap dan tindakan yang selalu berbasis atas karakter. (12) Mempunyai orientasi menciptakan pekerjaan sehingga tidak terlalu antri menunggu lowongan kerja. (13) Selalu menghargai waktu sehingga 
waktu-waktu terluang diisi dengan yang bermanfaat sehingga pantang bagi mereka waktu terbuang begitu saja. (14) Mereka adalah orang-orang yang berpandangan luas dan bijaksana. (15) Mereka adalah orang-orang yang tahan uji, tekun, tidak mudah untuk menyerah, jujur dan teguh dengan pendiriannya. (16) Selalu berusaha untuk meningkatkan keunggulan dan citra dari perusahaan. (17) Mempunyai kepekaan terhadap arti lingkungannya, artinya memiliki kemampuan untuk mengetahui potensi serta sumber-sumber ekonomi lingkungan setempat sehingga dapat difungsikan untuk usaha-usaha ekonomi, budaya dan sosial (Diana, Th, \& Rahmanto, 2014; Winarto, 2011).

Karakter yang menjadi ciri wirausaha tadi, tidak akan menjadi suatu kenyataan bila tidak diaplikasikan dengan baik dan benar dalam kehidupan sehari-hari. Adanya sifat taqwa, tawakal, zikir dan bersyukur akan memberi warna tersendiri untuk karakter-karakter tersebut. Ada jaminan yang Maha Kuasa, barang siapa yang taqwa kepada Nya maka akan mengadakan jalan keluar dan Dia akan memberi rezki dari arah yang tidak di sangka-sangka.

Tawakal adalah suatu sifat penyerahan diri kepada Allah, serta aktif dan tidak cepat menyerah. Berzikir selalu menyebut asma Allah dalam hati dengan merendahkan hati dan rasa takut dan tidak mengeraskan suara dalam keadaan selalu ingat kepadanya yang membuat hati tenang dan segala usaha dapat dilakukan dengan kepala dingin dan lancar, dibarengi rasa syukur juga akan membuat hati menjadi tenang dan damai. Selain itu kejujuran akan membuat hati ketenangan dan ketidak jujuran itu akan menimbulkan keragu-raguan. Jujur dalam segala kegiatan bisnis, menimbang, mengukur, membagi, berjanji, membayar hutang dan jujur dalam berkembang dengan orang lain akan membuat ketenangan lahir dan bathin.

Seorang muslim melakukan bisnis adalah dalam rangka ibadah kepada Allah, demikian pula kasih sayang diperoleh dalam bisnis akan dipergunakan kembali dijalannya. Keseharian yang dilakukan bagi seorang muslim, menunjukan kinerja dan produktifitas yang tinggi. Hal ini ditunjukkan dengan: pertama, bangun pagi dan Adzan. Dari seperangkat ajaran Rasulullah kepada umatnya agar mulai bekerja sejak pagi hari, selesai shalat subuh, jangan kamu tidur, bergeraklah, carilah rezki dari Tuhanmu . Para malaikat turun dan membagi rezki sejak terbit fajar sampai terbenam matahari. Kedua, toleransi, tenggang rasa, tepo saliro, lamak dek awak dan katuju dek urang harus dianut oleh orang -orang wirausaha, dengan demikian tampak orang itu supel, komunikatif, praktis, fleksibel, pandai melihat situasi dan kondisi, toleransi terhadap lapangan atau tidak kaku.

Ketiga, berzakat dan berinfak. Mengeluarkan zakat dan infak harus menjadi budaya muslim yang bergerak dibidang bisnis. Laba yang diperoleh harus disisihkan, sebagian untuk membantu anggota masyarakat yang membutuhkan. Dalam keyakinan ajaran Islam, sudah jelas bahwa harta yang dizakatkan dan diinfakkan tidak akan hilang melainkan menjadi tabungan yang berlipat ganda baik di dunia maupun di akhirat. Keempat, silaturahmi. Orang bisnis sering melakukan silaturahmi dengan partner bisnisnya, maupun dengan langganannya. Manfaat mempererat silaturrahmi disamping mempererat ikatan persaudaraan seringkali membuka peluang-peluang bisnis yang baru. Siapa yang ingin murah rezkinya dan panjang umurnya, maka hendaklah ia mempererat hubungan silaturrahmi.

Kewirausahaan mempunyai azas-azas sebagai berikut: (1) Kemampuan berkarya berazaskan DAMN (desire, ability, mean, needs) seseorang secara tekun, teliti, cermat, dan produktif; (2) Kemampuan untuk berkarya dalan azas kebersamaan berlandaskan etika bisnis yang sehat; (3) Kemampuan berkarya dengan semangat kemandirian; (4) Kemampuan 
memecahkan masalah berazas pada pengambilan keputusan secara sistematis, bertindak kreatif, inovatif dan komunikatif.

Masyarakat sekeliling secara langsung manfaatnya bisa dirasakan antara lain: (1) Menjadi tauladan bagi masyarakat sebagai pribadi (SDM) yang unggul sehingga bisa ditiru; (2) Bekerja keras, tekun, terampil, cermat dan produktif, serta tidak melupakan perintah agama akan menularkan hal-hal yang baik dan benar; (3) Memandirikan kediriannya, sehingga akan terjadi penyeimbang terhadap daya tampung tenaga kerja sehingga dapat mengurangi pengengguran; (4) Berusaha memberi bantuan kepada orang lain dan pembangunan social, sesuai dengan kemampuannya; (4) Bisa menularkan (mendidik) kepada orang lainnya untuk dapat mandiri, disiplin dan jujur dalam menghadapi pekerjaan serta hidup tidak boros, tidak berfoya-foya dalam hidup secara efisien.

Kewirausahaan memiliki berapa tujuan, yaitu (1) Meningkatkan jumlah wirausaha yang berkualitas; (2) Mewujudkan kesejahteraan masyarakat secara riil; (3) Membudayakan sikap, prilaku dan kemampuan kewirausahaan yang handal dan unggul; (4) Menumbuhkembangkan kesadaran dan orientasi kewirausahaan yang tangguh dan kuat, khususnya pada peserta didik maupun masyarakat. Sasaran dari kewirausahaan adalah: (1) Instansi pemerintah yang melakukan kegiatan usaha, organisasi profesi dan kelompokkelompok masyarakat; (2) Para pelaku ekonomi yang terdiri dari pengusaha kecil dan koperasi; (3) Para generasi muda yang umumnya putus sekolah, dan para calon wirausahawan.

Suatu hal yang perlu dikemukakan, marilah kita jawab bersama menurut keyakinan kita bahwa untuk menjadi wirausaha yang baik dan sukses syaratnya apa?. Jawabnya adalah kembali pada managemen dalam diri setiap individu untuk menerapkannya dengan tekat dan semangat yang kuat.

\section{MENINGKATKAN EKONOMI KERAKYATAN MELALUI KOPERASI DAN USAHA KECIL DAN MENENGAH}

Upaya untuk melakukan pembangunan ekonomi masyarakat secara terpadu perlu dibangun, membangun ekonomi kerakyatan tentunya dengan menggunakan strategi pembangunan saat ini. Ekonomi kerakyatan adalah struktur perekonomian yang dijiwai oleh semangat kemandirian, efisiensi pasar, serta keterpihakan pada upaya menumbuhkan usaha kecil , menengah dan koperasi. Kesenjangan dunia usaha yang kemudian berkembang menjadi perkembangan social antara yang kaya dengan yang miskin. Strategi pembangunan saat ini, yaitu 1) Menggiring kearah pembangunan ekonomi kerakyatan dengan cara membangun berbagai industri secara berbarengan/serentak baik industri kecil, menengah dan besar sehingga industri-industri tersebut sering menciptakan pasar bagi masyarakat; dan 2) Pemahaman sistem ekonomi yang terdapat dalam UUD 1945 pasal 33, adalah ekonomi yang sebesar-besarnya berpihak pada kemakmuran rakyat. Rakyat yang dimaksud dalam pasal tersebut adalah sebagian besar rakyat Indonesia.

Sistem ekonomi kerakyatan adalah merupakan azas ekonomi berdasarkan azas keterbukaan, kerjasama dan saling menguntungkan demi terciptanya masyarakat yang berkembang dan bertumbuh kearah kesejahteraan (Baswir, 2015; Soseco, 2011). Koperasi adalah badan usaha yang beranggotakan orang-orang atau badan hukum koperasi dengan melandaskan prinsip koperasi sebagai gerakan ekonomi kerakyatan yang berdasarkan atas azas kekeluargaan yang di dalamnya menumbuhkan sikap kemandirian setiap anggotanya untuk meningkatkan perekonomian dan kesejahteraan. Pengembangan sumber daya manusia 
(SDM) diarahkan untuk mendukung koperasi yang berkualitas dan pertumbuhan wirausaha baru yang mampu mengatasi pengangguran, menciptakan lapangan kerja dan mengentaskan kemiskinan (Baswir, 2002; Ridwan, 2014).

\section{KESIMPULAN}

Berdasarkan tulisan ini, maka dapatlah disimpulkan, yaitu 1) Krisis ekonomi yang berkepanjangan yang membuat kita tercekam oleh segala kekhawatiran karena masuknya arus globalisasi bisa diatasi melalui strategi yang menjaga dan memelihara human survival sehingga manusia sebagai individu bisa memanfaatkan peluang-peluang yang ada; 2) Kewirausahaan dan ekonomi kerakyatan perlu dikembangkan melalui pendidikan; 3) Ekonomi kerakyatan dalam koperasi dan UKM perlu disosialisasikan melalui pelatihan, pendidikan maupun penyuluhan; 4) Aktualisasi diri mewujudkan aspirasi secara mandiri mepukakan prasyarat pokok dalam tuntutan kebutuhan manusia.

\section{DAFTAR RUJUKAN}

Badan Penelitian dan Pengembangan Pusat Kurikulum Kementerian Pendidikan Nasional. (2010). Pengembangan Pendidikan Kewirausahaan. Jakarta: Badan Penelitian dan Pengembangan Pusat Kurikulum Kementerian Pendidikan Nasional.

Baswir, R. (2002). Ekonomi Kerakyatan vs. Neoliberalisme. Yogyakarta. Retrieved from https://www.spi.or.id/wp-content/uploads/PDF/001.pdf

Baswir, R. (2015). Ekonomi Kerakyatan vs . Neoliberalisme. Gema Keadilan, 2(1), 1-10. https://doi.org/10.3592/2

Diana, O., Th, D. S., \& Rahmanto, A. N. (2014). Penerapan Nilai-nilai Wirausaha Pada Pengusaha Indie Clothing di Surakarta. Surakarta. Retrieved from https://media.neliti.com/media/publications/116906-ID-none.pdf

Karo-karo, S. (2011). Pengembangan Kewirausahaan di Dunia Pendidikan dalam Era Globalisasi. In A. Siregar \& Poniadi (Eds.), Prosiding Seminar Internasional Pengembangan Kewirausahaan di Dunia Pendidikan. Medan: Unimed Press. Retrieved from http:/ / digilib.unimed.ac.id/4795/1/Fulltext.pdf

Muhdi, M., Senowarsito, S., \& S., L. (2012). Pendidikan Kecakapan Hidup (Life Skills) Melalui Child Friendly Teaching Model (Cftm) sebagai Dasar Membangun Karakter Siswa. E-Dimas: Jurnal Pengabdian Kepada Masyarakat, 3(1), 37-46. https://doi.org/10.26877/e-dimas.v3i1.252

Presiden Republik Indonesia. Sistem Pendidikan Nasional, Pub. L. No. 20 (2003). Indonesia.

Purnomo, M. (2015). Dinamika Pendidikan Kewirausahaan: Pemetaan Sistematis terhadap Pendidikan, Pengajaran, dan Pembelajaran. Jurnal Dinamika Manajemen, 6(1), 97-120. Retrieved

from https://journal.unnes.ac.id/nju/index.php/jdm/article/download/4300/4018

Ridwan, M. (2014). Ekonomi Kerakyatan. Jakarta: Lembaga Suluh Nusantara Bekerjasama dengan: American Institue For Indonesian Studies (AIFIS).

Sari, B., \& Rahayu, M. (2019). Pengaruh Pendidikan Kewirausahaan, Kebutuhan Akan Prestasi dan Efikasi Diri terhadap Intensi Berwirausaha Siswa SMA Muhammadiyah I Jakarta. IKRAITH-EKONOMIKA, 2(1), 22-31. Retrieved from https://media.neliti.com/media/publications/268009-pengaruh-pendidikan- 
kewirausahaan-kebutu-5d7f16c1.pdf

Shaumi, A. N. (2015). Pendidikan Kecakapan Hidup (Life Skill) dalam Pembelajaran Sains di SD/MI. TERAMPIL: Jumal Pendidikan Dan Pembelajaran Dasar, 2(2), 240-252. https://doi.org/10.24042/terampil.v2i2.1295

Solfema, S. (2017a). Entrepreneurship Cultural Cultivation for Students in Dealing Working World Challenges. In Proseding Seminar Nasional Pendidikan Nonformal Optimalisasi Peningkatan Mutu \& Kemandirian Dalam Menciptakan Lapangan Kerja Lulusan Prodi PNF Menghadapi Mea \& Bonus Demographi 2045 (Vol. 1, pp. 172-183). Bengkulu: Unit Penerbitan FKIP Universitas Bengkulu. Retrieved from http://repository.unib.ac.id/11759/1/16. Solfema ENTREPRENEURSHIP CULTURAL CULTIVATION FOR STUDENTS IN DEALING WORKING WORLD CHALLENGES.pdf

Solfema, S. (2017b). Pelatihan Ekonomi Produktif sebagai Usaha Pembangunan Karakter Perempuan dalam Meningkatkan Taraf Ekonomi Keluarga. In Prosiding Pengembangan Karakter Generasi Muda Bangsa. Padang: UNP Press.

Soseco, T. (2011). Ekonomi Kerakyatan Urgensi Konsep dan Aplikasi Sebuah Mimpi dan Peta Jalan Bagi Kemandirian Bangsa. Jurnal Ekonomi Dan Studi Pembangunan, 3(2).

Syamsi, I. (2010). Pendidikan Luar Sekolah sebagai Pemberdaya dalam Masyarakat. Diklus, 14(1), 66-76. Retrieved from https://media.neliti.com/media/publications/259971dampak-pendidikan-kewirausahaan-masyarak-8d2f0e2a.pdf

Tohani, E. (2015). Dampak Pendidikan Kewirausahaan Masyarakat (PKuM) dalam Konteks Pemberdayaan Masyarakat. Jurnal Ilmiah VISI PPTK PAUDNI, 10(1), 43-54. Retrieved from https://media.neliti.com/media/publications/259971-dampak-pendidikankewirausahaan-masyarak-8d2f0e2a.pdf

Usman, H. (2010). Model Pendidikan Kecakapan Hidup sebagai Alternatif Mengurangi Angka Kemiskinan. Jurnal Ilmu Pendidikan, 17(1), 7-14. https://doi.org/10.17977/jip.v17i1.2615

Winarto, H. (2011). Menuju Sukses Berwirausaha. Majalah Ilmiah Ekonomika, 14(1), 20-28. Retrieved from https://media.neliti.com/media/publications/23131-ID-menujusukses-berwirausaha.pdf

Wiratno, S. (2012). Pelaksanaan Pendidikan Kewirausahaan di Pendidikan Tinggi. Jurnal Pendidikan Dan Kebudayaan, 18(4), 453-466. https://doi.org/10.24832\%2Fjpnk.v18i4.101 